\title{
Research on the Construction of Intelligent Fire Protection Virtual Simulation Teaching Platform Based on Internet of Things
}

\author{
Guiling Sun, Sirui Wang, Hai Wang, and Yi Gao
}

\begin{abstract}
Aiming at the teaching challenge of cultivating integrated talents of Internet of things worldwide, and combining with the social background of fire rescue and management problems, We propose a virtual simulation teaching platform for the Internet of Things under the background of intelligent fire protection application. Based on the overall structure of the Internet of Things, different fire scenarios that cannot be simulated in real life are constructed through virtual simulation technology. OMNet++ technology is adopted to carry out virtual deployment of fire nodes for the overall structure of the building, and experiments such as cluster routing simulation, communication transmission simulation and wireless sensor node data acquisition simulation are designed. Meanwhile, a 3D fire data model is established using big data to simulate the best fire extinguishing scheme and the best escape strategy. From aspects of the Internet of Things system design and development, sensor principle and application, Internet of Things communication technology and Internet of Things data storage and application, we have realized the efficiency, innovation and challenge of the Internet of Things teaching. The virtual simulation teaching platform we built has been deployed and put into practical teaching, which has received positive response from students and achieved excellent teaching effect.
\end{abstract}

Index Terms-The Internet of things, intelligent fire protection, virtual simulation teaching.

\section{INTRODUCTION}

In recent years, along with the advance of technology and the rapid development of city construction, there are more and more high-rise buildings. However, the features of high-rise buildings, such as high floors, complex functions and various equipment, make it difficult for trapped people to escape in case of fire, which is likely to cause significant economic losses and casualties [1]. The old building fire performance is poor, disrepair, fire facilities maintenance is not in place and other problems also bring new difficulties to fire rescue. In addition, once a fire breaks out in a public gathering place with a large number of people, such as shopping malls and markets, it is easy to cause disastrous consequences. There have been numerous examples of costly fires around the world in recent years. A 14-hour fire broke out at Notre Dame de Paris on the night of April 15, 2019, devastating the 850-year-old architectural treasure, which

Manuscript received January 25, 2021; revised May 28, 2021.

The authors are with College of Electronic Information and Optical Engineering, Nankai University, Tianjin, China (e-mail: sung1@nankai.edu.cn, 2120200317@mail.nankai.edu.cn, wanghai@nankai.edu.cn,gaoyi@nankai.edu.cn). could take decades to rebuild. At least 38 people died in a fire at a warehouse in South Korea, on 29 April 2020. The fire situation is shown in Fig. 1. In view of various challenges faced by fire protection, how to make better use of emerging technologies to prevent fires from occurring and how to improve rescue and escape strategies have become urgent problems to be solved [2].

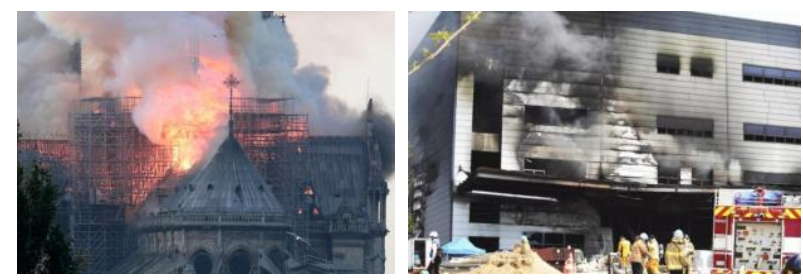

Fig. 1. The fire situation

The Internet of things is called the third wave of the development of the world's information industry after the computer and the Internet. It has a wide range of demands and application prospects in intelligent transportation, public safety, industrial monitoring, smart home and other aspects [3], [4]. Based on RFID, wireless sensor, cloud computing, big data and other high and new technologies, intelligent fire protection [5], [6] which applies the Internet of Things to fire rescue provides a new idea for dynamic simulation of fire scene, intelligent design of escape and rescue strategy, and standardized fire safety management. However, the lack of high-quality Internet of Things technical personnel has become a bottleneck restricting the development of the Internet of Things industry, so it has become an urgent problem to cultivate integrated Internet of Things technical personnel with engineering, innovation and design ability [7]. Therefore, many colleges and universities have set up the Internet of Things as a new direction for teaching and research. However, traditional verification experiments [8] make it difficult for students to truly master Internet of Things technologies through experimental courses. So it is necessary for the teaching of Internet of Things to construct the virtual simulation experiment project of "combination of virtual and reality".

Based on the social background and application requirements, this paper builds a virtual simulation experiment teaching platform with the background of intelligent fire protection. The platform adopts OMNet++ [9] simulation technology, through the simulation of a dangerous fire environment, combined with sensor, communication mode and other Internet of Things related technology, then solve the problem of how to deal with fire situations and choose the optimal escape strategy. This project guides 
students to realize integrated engineering projects with advanced technologies on the basis of multidisciplinary integration, trains students to analyze and solve practical engineering problems with Internet of Things theory, and develops students' engineering skills and innovation ability. The overall functional architecture of the virtual simulation experiment teaching platform built in this paper is shown in Fig. 2.

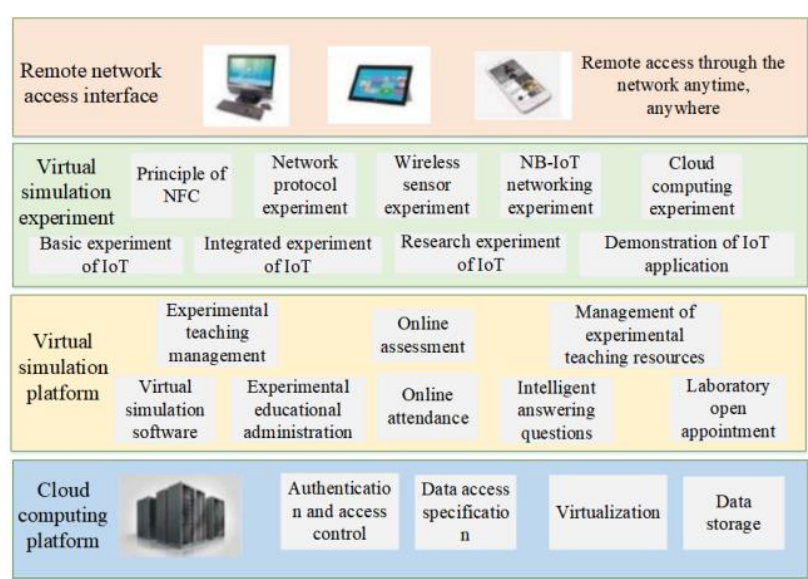

Fig. 2. The overall functional architecture of the virtual simulation experiment teaching platform.

\section{RELATED WORK}

With the rapid development of the Internet of Things technology and the urgent demand for talents in the direction of the Internet of Things, colleges and universities have set up courses related to the Internet of Things. However, the characteristics of the Internet of Things, such as strong interdisciplinary integration, extensive professional knowledge and high requirements for engineering practice, have brought great challenges to the teaching of the Internet of Things.

Most of the Internet of Things teaching at home and abroad adopts the way of setting up laboratories for practical operation teaching. He from Kennesaw State University built a laboratory development kit composed of Raspberry $\mathrm{Pi} /$ Arduino board and a set of Zigbee sensors to provide wireless communication in the class laboratory by combining software and hardware [10] .Vladimir proposed to apply pocket lab [11], [12] to the teaching of Internet of Things [13] By designing a small pocket laboratory and combining it with an online simulator, they enable students to experiment in the secure virtual environment of the simulator, get familiar with various electronic components and understand the practical engineering projects of the Internet of Things.This method takes advantage of the cheap and portable features of pocket labs to realize experiments anytime and anywhere.

The development of information technology puts forward new ideas for experimental teaching in universities, and the establishment of virtual simulation system based on software makes experimental teaching more flexible and comprehensive, which shows great advantages in practical teaching. Wang of Xi'an Technological University set up a comprehensive network practice and experiment platform [14] through the integration of network management software and network simulation software to achieve network application and maintenance, network equipment configuration, network management, network engineering design and other functions. Chen et al. proposed an arbitrary waveform generator based on DDS [15], which was used in the comprehensive virtual simulation experiment of digital electronic technology. Different types of signal waveforms could be observed through the virtual oscilloscope, so as to cultivate students' practical innovation ability and engineering application ability and achieve good results in the teaching of digital electronic technology.

Aiming at the advantages of constructing virtual simulation experiment teaching platform, how to combine it with actual experiment and apply it to Internet of Things teaching has become a problem we hope to solve. Based on the investigation and summary of previous work, this paper proposes a fully functional virtual simulation teaching system for intelligent fire protection that combines teaching and practice in a certain social application background.

\section{PROPOSED METHODS}

Intelligent fire protection system [16] is based on the overall structure of the Internet of things, combining with RFID [17], [18], wireless sensor, cloud computing, big data and other technologies, relying on wired, wireless, mobile Internet and other modern communication means, through the integration of existing data centers, improve the system alarm linkage, facility inspection and other functions. The mobile APP system is used to dynamically monitor and stereoscopic display the fire safety status of networked units, so as to comprehensively improve the fire safety management level and fire supervision efficiency of social units.The following part will analyze the virtual simulation teaching method proposed by us from the three aspects of the intelligent fire protection, teaching process and teaching content.

\section{A. Intelligent Fire Protection}

Intelligent fire protection is a typical application of the Internet of Things technology. It follows the three-layer network structure of IoT, namely, perception layer, transmission layer and application layer [19].The structure is shown in Fig. 3. The functions of the three layers under the background of intelligent fire protection are introduced as follows:

Perception layer: It realizes the acquisition and uploading of temperature, humidity, smoke sensation and other data in the nodes of Internet of Things, which provides data support for decision-making, management, operation and maintenance.

Transmission layer: By comprehensive application of NB-IoT, Lora, Zigbee and other network communication technologies, it is able to easily access various types of front-end sensory devices and conduct multi-level device access and management across the network.

Application layer: In the big data processing platform of the Internet of things, the intelligent fire protection system according to different fire conditions, combined with the distribution of fire hydrants and reserved emergency channels in the building, based on the principle of optimal 
path planning, uses multi parameter big data to conduct comprehensive analysis, and obtains the optimal escape strategy, which can guide the site selection of micro fire stations and fire hydrants. At the same time, the application layer adopts the form of Web services and app services, so that the fire department can grasp the real-time disaster monitoring information within the jurisdiction, timely carry out fire-fighting and rescue, and reduce the loss of life and property. Our system always revolves around the three-layer architecture of the Internet of Things, and designs simulation experiments hierarchically according to the principle of bottom-up, so that students can clearly master relevant knowledge.

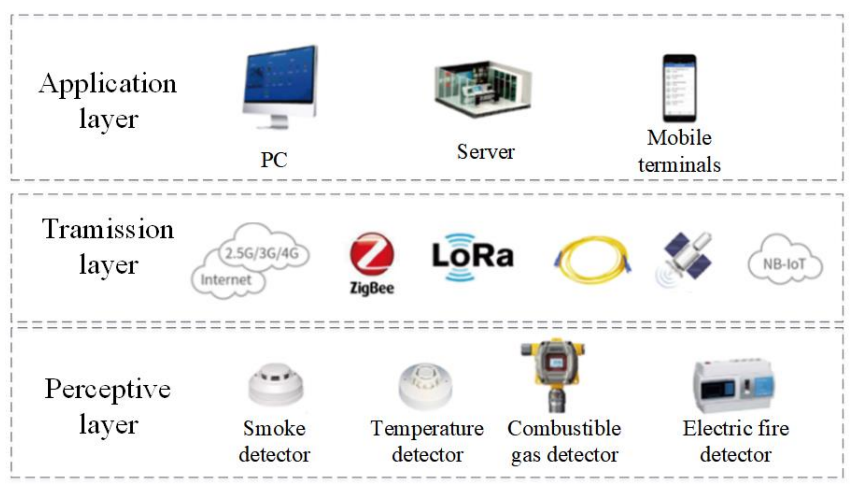

Fig. 3. The three-layer network structure of IoT.

\section{B. Teaching Process}

Guided by the practical project of intelligent fire protection, the teaching platform decomposes the project into several basic task units according to knowledge points, and each task unit is divided into several experimental steps. After mastering all the unit tasks, students begin to carry out the overall construction and comprehensive application of the project, so as to improve their ability of practice and innovation at the system level. At the same time, our teaching method pays more attention to the guidance and supervision role of teachers in the learning process of students, and adopts the combination of in-class learning and after-class interaction extension. The specific practical teaching process is shown in Fig. 4.

\section{Teaching Content}

Based on the overall architecture of the Internet of Things, we divided the Intelligent fire protection project into five tasks and 15 steps according to the key modules, as shown in Fig. 5. The system requires students to complete the relevant steps of each experimental unit, record data, analyze and submit relevant experimental results after fully understanding the application background and experimental principles of intelligent fire protection projects.

Through a complete study, students will master the theoretical knowledge and experimental means of the Internet of Things under the background of intelligent fire protection from the following aspects:

Design and development of Internet of Things system: Understand the development process of Internet of Things engineering project: application demand analysis, overall scheme design, functional design, system integration, system testing. Be familiar with the overall architecture of the
Internet of Things, and understand the functions of the perception layer, transport layer and application layer. Establish the concept of Internet of Things system design.

Principle of sensor: Understand the working principle and application of various wireless sensors and NFC technology. Master the control and debugging mode of wireless sensors, the temperature and humidity monitoring system required by intelligent fire fighting, and the application of sensors required by NFC patrol system.

Internet of Things communication technology: Realize virtual deployment of fire nodes on the overall structure of the building, complete virtual simulation experiment of cluster routing. Understand network routing protocol and Internet of Things data exchange technology, and master various wireless network communication technologies and typical applications.

Data storage and application of the Internet of Things: Master the Internet of Things database system, data mining technology, cloud computing service level and key technologies through unit experiments such as server construction, database and mobile terminal design and implementation.

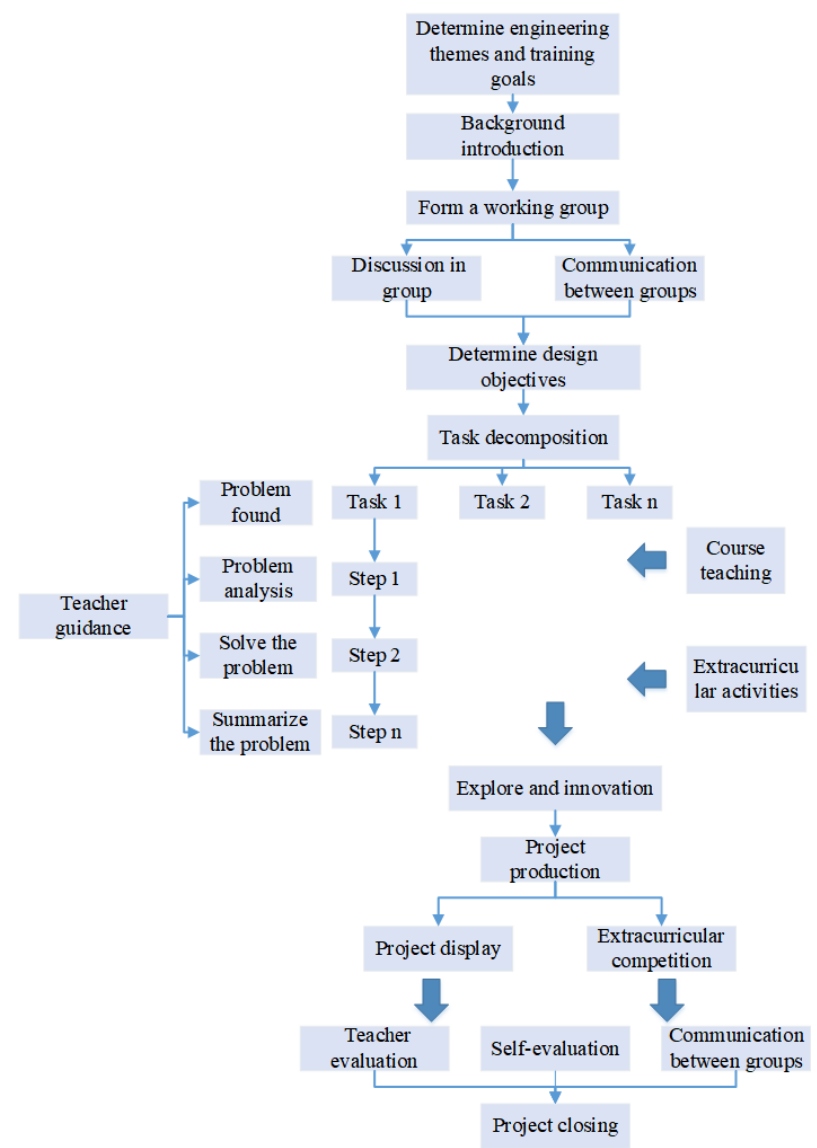

Fig. 4. The specific practical teaching process.

\section{RESUlTS}

The intelligent fire protection virtual simulation teaching system proposed in this paper has been built and put into practice, and has achieved good teaching effect. The system is deployed in the virtual simulation experiment teaching project sharing platform of Nankai University, with the domain name of iot.nankai.edu.cn and the IP address of https://222.30.40.128/. In this part, we will introduce the 
main functions of the virtual simulation system as well as its application scope and effects.

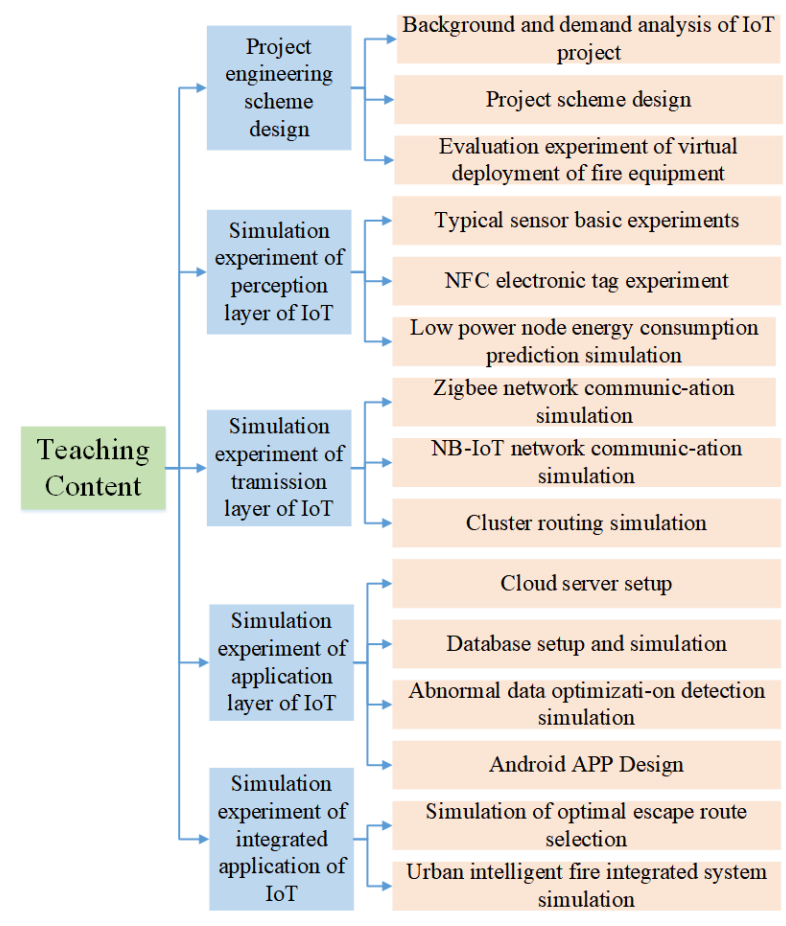

Fig. 5. Five tasks and 15 steps of the intelligent fire protection project.

\section{A. Functions}

The virtual simulation system constructed in this paper has comprehensive functions, complete management mode and high usability. The overall functions mainly include experimental background introduction, hardware platform construction, virtual imitation experiment implementation, experiment report writing, evaluation mechanism, fire escape drill, fire virtual exhibition hall and map library and so on. The system interface is shown in Fig. 6.

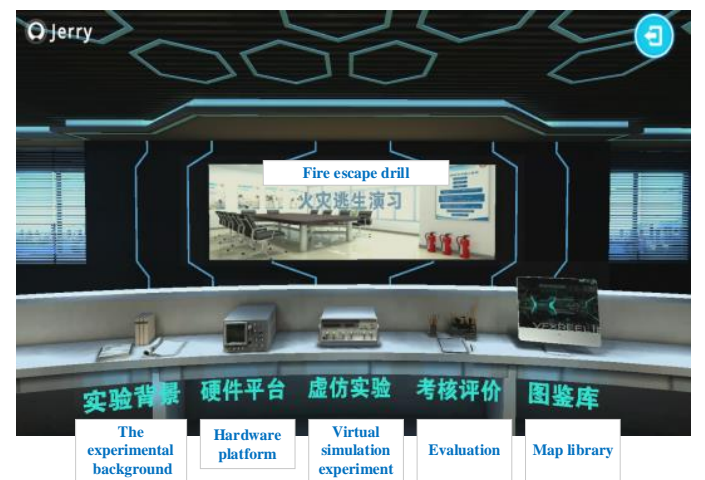

(a)

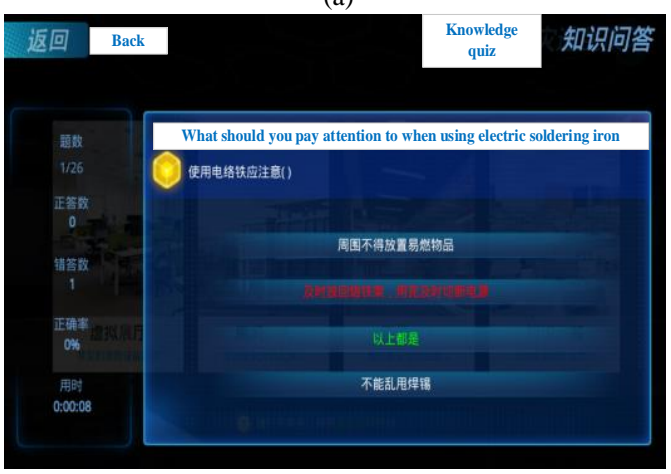

(b)

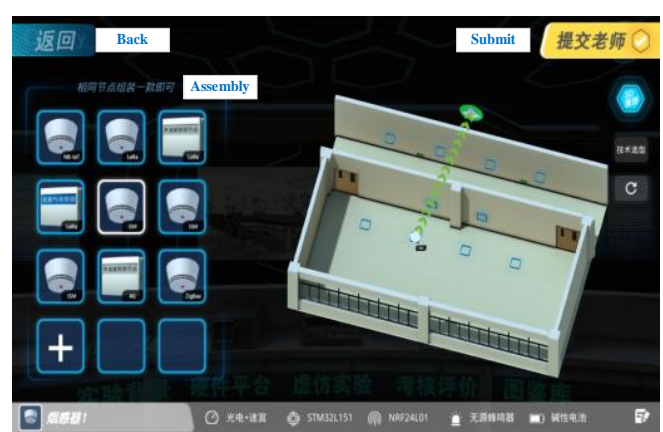

(c)

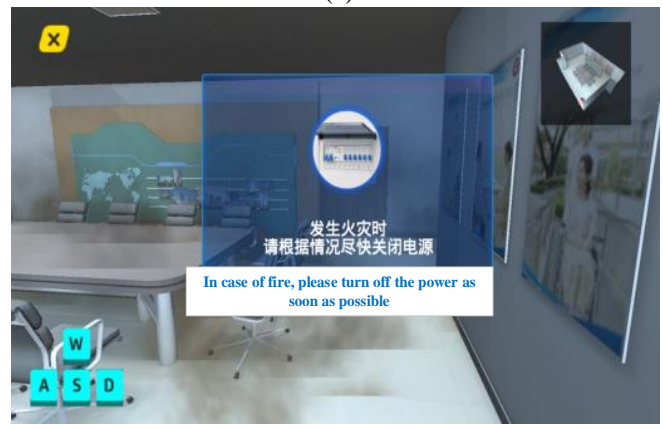

(d)

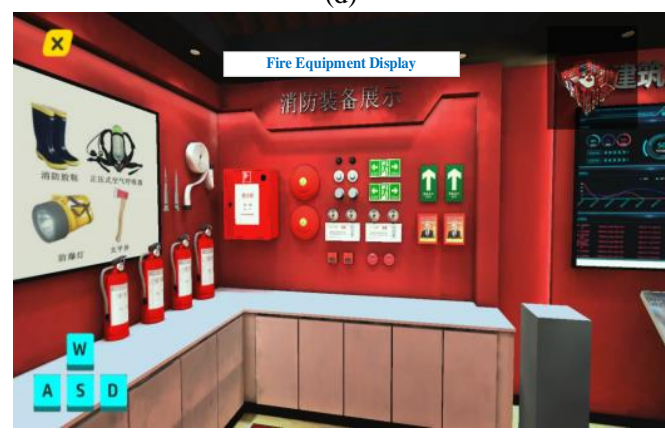

(e)

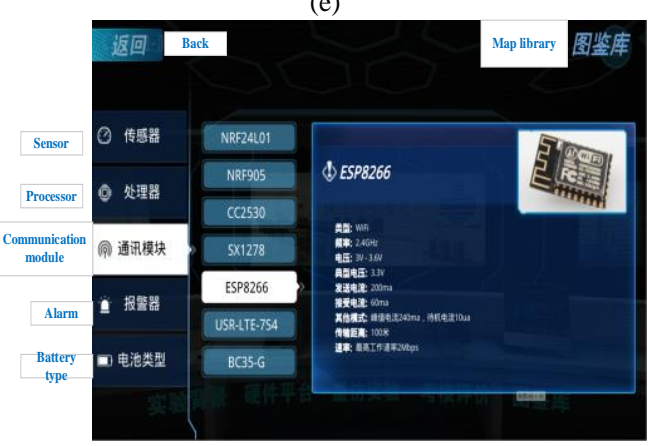

(f)

Fig. 6. (a) System initial function interface. (b) Assessment and evaluation mechanism - fire knowledge question and answer interface. (c) Internet of Things deployment experiment for real application scenario. (d) Campus scene fire escape drill. (e) 3D virtual firefighting exhibition hall. (f) Map library.

Mastery oriented intelligent evaluation system: The conventional method that students submit experimental results and then get teachers' evaluation has some problems in the actual experimental teaching process: There is a certain lag in the students' obtaining the correct results, and they cannot correct the mistakes in the experiment process in time; It is difficult for teachers to make clear the practical problems encountered in the process of students' operation and realize the detail of error correction. Therefore, we set up a judgment system throughout the whole experiment process, which sends out relevant theoretical hints for each step of errors in real time, guides students to think independently. Through 
the whole process and real-time evaluation, it not only deepens students' learning impression, but also saves teachers' workload in evaluation.

Various assessment and evaluation mechanisms: We adopt the strategy of combining various assessment methods to increase the interest of learning. Before the experiment began, the system used the game to ask questions about laboratory fire knowledge, set achievement goals in different dimensions, and won corresponding medals after achieving them. In the experiment, the system conducts real-time evaluation and examination, which is combined with the intelligent evaluation system to deepen the students' mastery degree. After the experiment, students submit the experiment report with pictures and text to complete the experiment.

Virtual simulation experiment system based on real application scenario: The system sets up two practice scenarios of "small places where users are scattered" and "banks that need to install intelligent fire protection system". Students need to think independently to choose the right network framework, networking mode, relevant protocols and node selection for the two scenarios. Through the simulation of different real scenes, students' flexible mastery of knowledge related to intelligent fire protection system is strengthened. The system adopts bird's eye view and supports $3 \mathrm{D}$ roaming. Each link is supplemented by corresponding "small blackboard" function. Students can find the current link knowledge point at any time, which has strong authenticity and ease of use.

The campus scene fire escape simulation exercise based on Unity3D: Taking real campus scenes as the background, the system designed different types of virtual fires, such as classroom building fire and office small fire, based on Unity3D. It adopted the whole-process voice guidance to guide students to avoid, make decisions and take correct actions by moving, and explore correct escape strategies. The system also sets up a 3D virtual firefighting exhibition hall, where students can learn about more than 20 kinds of firefighting equipment.

Humanized interface design: The system adopts the way of no-registration login, and the mobile phone number can log in directly through verification, which eliminates the trouble for users to record the account and password. There are two kinds of accounts: professional students and popular science users. After logging in, popular science users can use the fire drill module without any authentication, which is suitable for the promotion of all teachers and students in the school. The system's unique map library mode is convenient for students to view the real pictures and technical parameters of various hardware modules such as sensors, processors, communication modules, alarms and batteries.

\section{B. Application Scope and Effect of the System}

At present, the intelligent fire protection virtual simulation teaching platform built by us has been applied to modern Information Technology Experiment of Nankai University. After optimization and improvement, it has been applied to compulsory courses of the college. The teaching scope covers 3 colleges and 8 majors, serving over 500 students.

We conducted a feedback survey on the students who completed the course, and the survey showed that almost all the students indicated that the virtual simulation experiment course had certain advantages over the traditional experiment course, and they thought the system we constructed was more interesting. Intelligent fire protection system enables students to have a deeper understanding of fire safety knowledge while mastering the professional knowledge of Internet of things.

In the comments we collected from students about the course, some students said:

"Through the study of this course, I not only understand the importance and safety of intelligent fire fighting, but also understand that its "wisdom" is supported by the Internet of Things technology, which further increases my interest in this technology of the Internet of Everything."

"Against the background of Covid-19 epidemic this year, the intelligent fire fighting virtual simulation system makes full use of network resources, introduces advanced modern information technology into the classroom, and provides a perfect simulation operation platform for us who cannot enter the laboratory at home."

Students have given the course a lot of positive feedback, and the teacher in charge of the course also said: The teaching effect of virtual simulation experiment course is quite good. From the submitted experiment report, it can be seen that the students have strengthened their mastery of the theoretical knowledge of the Internet of Things, reflecting their strong interest in the experiment of the Internet of Things, and at the same time, they have achieved a higher degree of completion.

In order to promote the virtual simulation teaching results, the teaching team actively wrote teaching reform papers and participated in forums and conferences, which obtained a lot of good responses in China and promoted the related experimental teaching reform.

\section{CONCLUSIONS}

Based on intelligent fire protection scenarios, this paper puts forward the virtual simulation teaching platform of the Internet of Things, by combining the RFID, wireless sensor, cloud computing, big data and other high and new technology, has completed three major objectives: IoT system teaching and practice, the real scene of fire escape simulation exercises, publicity and education on fire control safety knowledge. The innovative work of this paper includes:

Taking "intelligent fire fighting" as the main line, the system design is strengthened by the form of virtual simulation, and the core technology is mastered by the form of practical operation. Through virtual simulation technology, different fire scenarios that cannot be simulated in real life are constructed, and the combination of virtual and reality is highlighted in the experiment process; Through the simulation experiment of the optimal escape strategy, the students' innovative practice ability of the Internet of Things application layer was cultivated. Based on the numerical simulation technology and the big data technology of the Internet of Things, the students have a deep understanding of the "data-based and service-centered" characteristics of the Internet of Things; This paper comes from the latest scientific research achievements made by the project team in the field 
of smart city and smart security. According to the characteristics of undergraduate experimental teaching, the high-level scientific research achievements are condensed into knowledge points. Virtual simulation experiments are conducted to realize the visualization of theoretical knowledge.

\section{CONFLICT OF INTEREST}

The authors declare no conflict of interest.

\section{AUTHOR CONTRIBUTIONS}

Guiling Sun contributed to the design of teaching framework and ideas, as well as the overall construction of the teaching platform; Sirui Wang contributed significantly to algorithm design of the platform and wrote the manuscript; Hai Wang completed the platform interface design and contributed to the teaching application; Yi . Gao designed the hardware part of the experiment and contributed to the platform IoT experiment deployment; All authors had approved the final version.

\section{ACKNOWLEDGMENT}

This material is based in part upon work supported by the project--- "Reform and Practice of Electronic Information Innovation and Compound Talent Training Mode Based on "5C" Concept" under Project Numbers B201005508. The project has been approved as the 2019 Tianjin virtual simulation experiment teaching project in China.

\section{REFERENCES}

[1] B. Ning, A. Ding et al., "State-of-the-art high-rise building emergency evacuation behavior - ScienceDirect," Physica A: Statal Mechanics and Its Applications, 202.

[2] X. Fang, Z. Di, and W. Jun, "Fire safety management information system design for key social organizations," presented at Fifth International Conference on Intelligent Systems Design \& Engineering Applications. IEEE Computer Society, 2014.

[3] M. Chernyshev, Z. Baig, O. Bello et al., "Internet of things (IoT): Research, simulators, and testbeds," IEEE Internet of Things Journal, 2017.

[4] L. Atzori, A. Iera, and G. Morabito, "The internet of things a survey," Computer Networks, vol. 54, pp. 2787-2805, 2010.

[5] N. Savitha and S. Malathi, "A survey on fire safety measures for industry safety using IOT," presented at 2018 3rd International Conference on Communication and Electronics Systems (ICCES), 2018.

[6] A. Ngenzi, "Design of an IoT-based fuzzy approximation prediction model for early fire detection to aid public safety and control in the local urban markets," Symmetry, 2020, vol. 12, no. 12, p. 1391.

[7] Y. M. Leong and C. Letchumanan, "Effective learning in higher education in Malaysia by implementing internet of things related tools in teaching and introducing IoT courses in curriculum," presented at 2019 1st International Conference on Artificial Intelligence and Data Sciences (AiDAS), 2019.

[8] V. M. Cvjetkovic and Uros Stankovic, "Arduino based physics and engineering remote laboratory," International Journal of Online Engineering, 2016, vol. 13, no. 1, pp. 560-574.

[9] X. Xian, W. Shi, and H. Huang, "Comparison of OMNET++ and other simulator for WSN simulation," presented at 3rd IEEE Conference on Industrial Electronics and Applications, IEEE, 2008.

[10] J. He et al., "Integrating internet of things (IoT) into STEM undergraduate education: Case study of a modern technology infused courseware for embedded system course," Frontiers in Education Conference, IEEE, 2016.

[11] C. Madritsch et al., "Work in progress: Using pocket labs in master degree programs," Interactive Collaborative Learning, 2017.
[12] T. Klinger and C. Madritsch, "Use of virtual and pocket labs in education (demo)," in Proc. 13th International Conference on Remote Engineering and Virtual Instrumentation (REV), pp. 261-262, UNED, Madrid, Spain, 24-26 February 2016.

[13] V. M. Cvjetkovic, "IoT teaching with pocket labs," presented at International Conference on Interactive Collaborative Learning, Springer, Cham, 2017.

[14] H. Wang and J. C. Lei, "Construction of network comprehensive experimental platform based on virtual simulation," in Proc. the 5th International Conference on Social Science and Higher Education(ICSSHE-19), 2019.

[15] C. Long et al., "Research on comprehensive virtual simulation experiment reform of digital electronic technology," Research and Exploration in Laboratory, 2017.

[16] J. S. Chou, M. Y. Cheng, Y. M. Hsieh et al., "Optimal path planning in real time for dynamic building fire rescue operations using wireless sensors and visual guidance," Automation in Construction, 2019, vol. 99, pp. 1-17..

[17] X. Jia, O. Feng, T. Fan, and Q. Lei, "RFID technology and its applications in internet of things (IoT)," in Proc. 2nd IEEE conference on Consumer Electronics, Communications and Networks (CECNet'12), pp. 1282-1285, 2012.

[18] C. Sun, "Application of RFID technology for logistics on internet of things," in Proc. AASRI Conference on Computational Intelligence and Bioinformatics, pp. 106-111, 2012.

[19] J. Gubbi, R. Buyya, S. Marusic, and M. Palaniswami, "Internet of things (IoT): A vision, architectural elements, and future directions," Future Generation Computing System, vol. 29, pp. 1645-1660, 2013.

Copyright $\odot 2021$ by the authors. This is an open access article distributed under the Creative Commons Attribution License which permits unrestricted use, distribution, and reproduction in any medium, provided the original work is properly cited (CC BY 4.0).

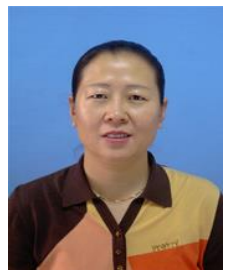

Guiling Sun received the Ph.D. degree from Nankai University, in 2004. She is also the vice director of the Tianjin Institute of Communications, the vice director of the EDA Technology Research Society, China, and the leader of Electronic Technology Experiment and Practice Teaching Team, Tianjin. She has published more than 130 articles and two research monographs in a number of areas about wireless sensor networks, the Internet of things, compressed sensing, information detection, and intelligent control systems and signal processing. She has won the honor of the Famous Teacher and the Excellent Teaching Team in Tianjin, China. She is currently a Professor with Nankai University.

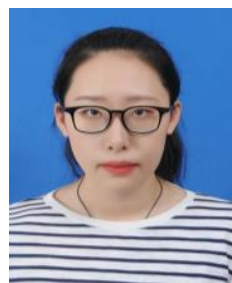

Sirui Wang received the bachelor's degree from Nankai University in 2020. She is pursuing the master's degree in electronic information and optical engineering at Nankai University. Her research interests include the Internet of things, compressed sensing and artificial intelligence algorithms.

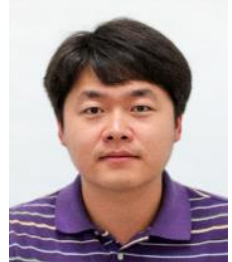

Hai Wang received his master's degree from the University of New South Wales, Australia, in 2009. Currently, he is working at the College of Electronic Information and Optical Engineering, Nankai University. His research interests include design of analog/digital circuit, RF microwave circuit and IOT technology.

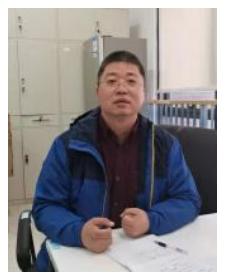

Yi Gao received the Ph.D. degree from Nankai University in 2010 . He is currently working at the College of Electronic Information and Optical Engineering, Nankai University. His main research directions: Internet of things, intelligent detection and control 